The Demand for Electricity in Virginia

Author(s): Michael P. Murray, Robert Spann, Lawrence Pulley and Edward Beauvais

Source: The Review of Economics and Statistics, Vol. 60, No. 4 (Nov., 1978), pp. 585-600

Published by: The MIT Press

Stable URL: http://www.jstor.org/stable/1924252

Accessed: 19/02/2014 15:55

Your use of the JSTOR archive indicates your acceptance of the Terms \& Conditions of Use, available at http://www.jstor.org/page/info/about/policies/terms.jsp

JSTOR is a not-for-profit service that helps scholars, researchers, and students discover, use, and build upon a wide range of content in a trusted digital archive. We use information technology and tools to increase productivity and facilitate new forms of scholarship. For more information about JSTOR, please contact support@jstor.org. 


\title{
THE DEMAND FOR ELECTRICITY IN VIRGINIA
}

\author{
Michael P. Murray, Robert Spann, Lawrence Pulley, \\ and Edward Beauvais*
}

\section{Introduction}

L ESTER Taylor concluded his recent survey of electricity demand studies (1975) with an overview of the deficiencies of those studies and a program for future research. ${ }^{1}$ In his remarks Taylor noted that most empirical studies have been limited to a single customer class, residential consumers, that many studies have relied on highly aggregated data such as national time series or cross sections of states, that few have explicitly accounted for the declining block rate structure of residential electricity prices and none has considered the two-part tariff aspect of commercial and industrial demand, and that none has analyzed seasonal variations in electricity demand, especially seasonal variations in kilowatt peak demands. This paper presents a demand study of the Virginia Electric Power Company $^{2}$ (VEPCO) that is not lacking in any of the aforementioned dimensions.

Residential, commercial, and industrial demands are analyzed using monthly data from each of VEPCO's nine Virginia billing districts

Received for publication February 28, 1977. Revision accepted for publication November 2, 1977.

* Duke University, Virginia Polytechnic Institute and State University at Reston, Brandeis University, General Telephone and Electronics Service Corp., respectively.

The authors are indebted to the Virginia State Corporation Commission for its financing of this research (Spann and Murray, 1976). Edgar Olsen, Roger Sherman, and participants in the University of Virginia Micro Workshop generously read and critiqued an earlier draft. We are also grateful to VEPCO and to various offices of the State of Virginia for their cooperation in providing data, and to two anonymous referees.

Murray and Pulley share responsibility for the theorizing of section II, and the corresponding empirical results of section VI. Spann and Beauvais are primarily responsible for the work in sections III and IV, and the corresponding empirical results in section VI. Murray is chiefly responsible for section VII. We all share responsibility for the conclusions drawn in the text. The appendix is the sole responsibility of Murray and Pulley.

1 Taylor (1975), pp. 107-108. Readers interested in comparing our empirical results with those obtained by earlier researchers will find Taylor's article very useful. Taylor's paper also contains a comprehensive bibliography of the electricity demand literature.

${ }^{2}$ In 1975 , VEPCO provided $72 \%$ of the total kilowatt hours consumed in Virginia. over the period $1958-1973 .{ }^{3}$ Seasonal variation in the kilowatt hour demand coefficients is permitted, and the structure of VEPCO's (summer) monthly kilowatt peak demand is estimated (from 1960-1973 data) to allow some conclusions to be drawn about VEPCO's peak load problems. For each customer class, and for peak demand, more careful attention has been given to the specification of appropriate price variables than has been customary in the past studies. In an appendix, Murray and Pulley contrast two sets of forecasts for residential kilowatt hour demand, one based on the model of this paper and the other based on a model-free methodology pioneered by Box and Jenkins (1970). The outcomes of these two forecasting methods are compared with actual demands for a limited number of years.

We come to four major conclusions. First, both economic growth and increases in the real price of electricity tend to induce load factor ${ }^{4}$ deterioration because kilowatt peak demand income elasticities are higher, and price elasticities lower, than the corresponding kilowatt hour demand elasticities. This finding suggests that in a period of rising real incomes and rising real electricity prices, electric utilities will face an increasing need for means, such as time of day pricing, to alleviate peak load problems. Second, demand elasticities can vary substantially within a company's service area, implying that there may be regional differences in the impact of rate changes on customers, and that uniform patterns of rate changes and of economic growth within a company's service area may cause uneven patterns in the need for new transmission and generating facilities. Third, and most tentatively, alternative fuel prices should be accounted for in forecasting kilowatt hour demand because industrial electricity users are sensitive to these prices. And

3 There were actually eleven VEPCO billing districts in Virginia during the sample period, but two of these served primarily other states and contained only a few customers in Virginia. In 1974, VEPCO redefined the geographic boundaries of its billing districts, so we were limited to pre-1974 data.

${ }^{4}$ Load factor is the ratio of actual annual kilowatt hours delivered to potential annual kilowatt hour output. 
fourth, the choice between modeled and modelfree forecasts is not trivial; separate forecasts of each of residential demand's determinants, coupled with structural estimates of the demand relationship, yield very different forecasts of electricity demand than does direct forecasting of electricity demand.

As Taylor has emphasized, ${ }^{5}$ econometric models of residential electricity demand are much better developed than those for industrial, commercial or peak demands. In this paper we have sought to improve on past efforts in all four areas. Our residential model, which accounts for both the declining block structure of residential prices, and the dynamics of appliance accumulation, has benefited from the past work of others; our industrial, commercial, and peak models make notable advances in that they account for the two-part tariff structure of industrial and commercial price schedules and differentiate among seasons and between long run and short run demand changes. In all, the methods used throughout are consistent enough to permit reasonable comparisons among, and combinations of, customer class results.

The next three sections discuss the theoretical models underlying the demand parameter estimates. Section V details the data used, while sections VI and VII contain the empirical results. Concluding remarks are made in section VIII.

\section{Residential Consumption}

Two major stumbling blocks to modeling residential electricity consumption are the complex residential electricity price schedules and the dynamic responses of households to changes in their long run desired appliance holdings. Other factors to be accounted for are climate (especially temperature), income, appliance prices, and the prices of alternative fuels.

Residential electricity customers typically face a declining block rate structure. For example, the first fifty kilowatt hours (kwh) purchased may cost $5 \varnothing$ each, the next hundred $3 \notin$ each, and so on; the intervals over which the marginal price is held constant are called "blocks." For each customer, the prices in blocks below one's own demand are inframarginal; prices in blocks above one's own demand are superfluous. The response of a single customer to a change in a block's price

\footnotetext{
s Taylor (1975), pp. 107-108.
}

will vary as that price is marginal, inframarginal, or superfluous. For inframarginal prices, the effect of a price change will be the same as for an income change equal to minus the price change times the block length; for marginal prices, a price change will induce both income and substitution effects; for superfluous prices, a price change has no effect.

Since in the aggregate most blocks will play different roles for different customers, the price coefficients in the demand equation will depend on the distribution of $\mathrm{kwh}$ demands across customers. Only in the lowest blocks, above which virtually all usages lie, can we assume that the effect of price changes is homogeneous across customers; in these blocks, the prices are inframarginal for everyone. Indeed, one test of the validity of our demand model, suggested by Taylor (1975), ${ }^{6}$ is to verify if the income coefficient is of the same magnitude (but opposite sign) as the coefficients of the prices of lowest kwh blocks when these block prices are weighted by their block lengths.

In the sample period there are nine price blocks; multicollinearity among them requires reduction in their number to three. The first five prices are assumed generally inframarginal (from 0 to $210 \mathrm{kwh}$ ). To facilitate comparison with the income coefficient, a weighted sum (with block lengths as weights) of these prices forms the first price variable. The sixth and seventh blocks' prices are summed, as are the eighth and ninth blocks' prices, to form the other two price variables. The empirical results of the paper are not sensitive to alternative groupings.

A definitive empirical treatment of the dynamics of residential electricity demand will not be possible until detailed data on electrical appliances and appliance prices become available. Without such data it is necessary to make simplifying assumptions if the dynamics of consumer behavior are to be included in a model of residential electricity demand. A very tractable model follows from the assumption that utilization rates are constant and the same for all appliances. ${ }^{7}$ This permits kwh consumption to be written as

\footnotetext{
6 Taylor (1975), p. 80. A theoretical paper by Nordin (1976) written after this paper, shows that Taylor's test is, at best, an approximation to a proper test; by implication, our test results are not conclusive.

${ }^{7}$ See Taylor (1975) for detailed discussions of several approaches to dynamizing electricity demand models.
} 


$$
K=\mathrm{kwh}=r A
$$

where $r$ is the utilization rate and $A$ is total appliance holdings measured in kw capacity. If, further, we assume $r$ is a log-linear function of some $n$ variables, the $X_{i}$ (prices, income, temperature, etc.), we can write

$$
\ln K=\sum_{i=1}^{n} \beta_{i} X_{i}+\ln A .
$$

To circumvent the need for data on $A$, we assume households are in a process of continuous partial adjustment towards a desired level of appliance holdings. Desired appliance holdings, $A^{*}$, are assumed to depend multiplicatively on a vector of $m$ variables, the $Z_{j}$, some of which may also appear among the $X_{i}$. Thus,

$$
\ln A^{*}{ }_{t}=\sum_{j=1}^{m} \alpha_{j} Z_{j t-1} \text {. }
$$

We also assume the partial adjustment process takes the form

$$
\begin{aligned}
\ln A_{t}-\ln A_{t-1}=\phi\left(\ln A_{t}^{*}-\ln A_{t-1}\right) & \\
0 & <\phi \leq 1 .
\end{aligned}
$$

So the demand relationship can be expressed as

$$
\begin{aligned}
\ln K_{t} & -(1-\phi) \ln K_{t-1}=\sum_{i=1}^{n} \beta_{i} \\
& \times\left(X_{i t}-(1-\phi) X_{i t-1}\right)+\sum_{j=1}^{m} \alpha_{j} \phi Z_{j t-1} .
\end{aligned}
$$

And if households adjust instantaneously $(\phi=$ $1)$, as we find they do, the model becomes

$$
\ln K_{t}=\sum_{i=1}^{n} \beta_{i} X_{i t}+\sum_{j=1}^{m} \alpha_{j} Z_{j t-1}
$$

The equal utilization rate assumption is thoroughly untenable across winter and summer; air conditioners are unused in winter, while heaters are inactive in summer, and these two appliances are an important part of the whole stock. Our approach is to conceptualize two distinct capital stocks, one for summer and one for winter. This implies that the time lags between observations are not uniform since the lag within seasons is two months (in our bimonthly data) while the lag between seasons is six months, so we have added the assumption that all summer appliance stock adjustment occurs during the winter, and conversely for the winter appliance stock. ${ }^{8}$ In this conceptualization, the $X_{t-1}$ and $Z_{t-1}$ in equations (1) and (1') are the means of the $X$ 's and $Z$ 's in the season of $t$ for the previous year (i.e., if $t$ is in the summer of 1971, $Z_{j t-1}$ refers to the mean $Z_{j}$ in the summer of 1970).

Equation (1) is the demand model we estimate. The $X_{i}$ are (the logs of) the three electricity price variables described above lagged one period, one or two temperature variables, per capita permanent income, and dummy variables to permit bimonthly shifts in the demand function. The $Z_{j}$ are (the logs of) the three electricity prices, per capita permanent income, and the price of \#2 heating oil. Kilowatt hour consumption is measured in per capita terms.

Responses to price and income changes are probably not instantaneous, but rather are spread over several periods. Unfortunately, multicollinearity precludes the inclusion of further lagged prices, so the price coefficients reflect the effects of both current and lagged prices; this consideration should be kept in mind when interpreting residential short run price elasticities below. A permanent income measure, discussed further in section $\mathrm{V}$, is used to reflect the lagged response of households to income changes.

\section{Commercial and Industrial Consumptions}

Commercial and industrial electricity demands are similar to one another and dissimilar from residential demands. The relative price of electricity, the level of economic activity, the prices of alternative fuels, and weather are the primary variables. Once again the complexity of the rate structure and the dynamic adjustment of users to their desired electricity using capital stocks are the principal problems.

Typically, commercial and industrial users face (different) two-part, declining-block tariffs. The first part of the tariff is a declining-block price system for total kwh demanded in a month, called an "energy charge." The second part of the tariff is a declining-block price system for the maximum rate of kilowatt ( $\mathrm{kw}$ ) consumption during a 15,30 , or 60 minute interval, called a "demand charge." As in residential demand, each

\footnotetext{
8 The residential demand model was also estimated under the assumption that there is a single homogeneous capital stock, without the assumption of all adjustment occurring between seasons. The empirical results were basically the same as those for the two stock models presented here.
} 
block price (for both energy and demand charges) will vary from being marginal, inframarginal, or superfluous from one customer to another.

The dynamic adjustment problem is somewhat different in the commercial and industrial sectors than in the residential sector. The highly integrated nature of the production process makes the assumption of instantaneous adjustment of the utilization rate and lagged adjustments of stocks untenable; both the utilization rate and capital stocks are likely to respond slowly to changes in demand determinants. Rather than attempt to disentangle the utilization and stock adjustments we simply assume a distributed lag structure for electricity demand

$$
\begin{aligned}
\ln K_{t}= & \sum_{i=1}^{m} \gamma_{i} V_{i t}+\lambda_{1} \ln K_{t-1} \\
& +\lambda_{2} \ln K_{t-12}
\end{aligned}
$$

where $\lambda_{1}, \lambda_{2}$, and the $\gamma_{i}$ are parameters, the $V_{i}$ are the determinants of demand, and $K$ is kilowatt hours demanded. Both $K_{t-1}$ and $K_{t-12}$ are included in order to capture both month to month and year to year adjustments; $K_{t-1}$ captures the usual short run lags in response while $K_{t-12}$ accounts for both seasonal factors and the dynamic adjustment of the season-specific capital stocks. The $V_{i}$ are all measured in logs so the $\gamma_{j}$ are short run elasticities and the $\gamma_{j}$ divided by $\left(1-\lambda_{1}-\right.$ $\lambda_{2}$ ) are the long run elasticities. The $V_{i}$ are (the logs of) real marginal energy and demand prices, temperature, a measure of economic activity, the real price of oil, and the average price of electricity. In the commercial sector about the only possible substitution for electricity is in heating; for this reason, the price of oil is included only in the winter regressions for commercial customers.

The limitations of the data make it impracticable to model the complexity of interactions between energy and demand charges; therefore representative marginal prices are constructed. For marginal energy charges we use the marginal cost of increasing kwh from one half of average $\mathrm{kwh}$ to one and a half average $\mathrm{kwh}$, at average $k w$ demand. For marginal demand charges the construction is analogous, with the roles of $\mathrm{kw}$ and kwh reversed. ${ }^{9}$ Since the marginal prices are

\footnotetext{
${ }^{9}$ For commercial users, an average kilowatt level is assumed to be $10 \mathrm{kw}$; an average $\mathrm{kwh}$ demand is assumed to be $2,190 \mathrm{kwh}$. For industrial users, the averages are $7,500 \mathrm{kw}$
}

not complete representations of the price structure, average electricity price is included to capture otherwise masked price responses.

Two measures of economic activity are used. In the commercial sector total taxable income is used to reflect commercial activity. In the industrial sector, in which there is great variance across industries in electricity usage, an electricintensity-industrial-activity index was constructed by weighting industry employments by the 1971 national ratios of electricity consumption to employment for the industries. ${ }^{10}$ This measure is especially attractive since it can reflect differing cyclical activity patterns across industries as well as differing electricity intensities.

Of the three major alternatives to electricity (gas, coal, and oil), only oil is represented in the model by a price variable, because of multicollinearity problems. ${ }^{11}$

\section{Monthly Peak Kilowatt Demand}

High storage costs make it uneconomical for electrical utilities to use storage to smooth out production in the face of uneven temporal patterns of demand. Instead, utilities choose their productive capacity so as to be able to meet "peak demands" at the moment they arise, an approach that results in excess capacity in off peak periods. The "load factor" of a utility, the ratio of actual kwh usage to potential kwh output in a period, is a measure of capacity utilization; a low load factor implies that during much of a period considerable generating capacity has lain idle.

Despite the importance of kw peak demand for generating capacity and financial planning, nowhere in the economic literature on electricity demand are there estimates of monthly kilowatt

and $2,737,500 \mathrm{kwh}$. Since for commercial customers the lower marginal demand charge is always zero, this variable never appears in the regressions.

10 The industry employments were drawn from the March and September reports of the Virginia Employment Commission. The ratios of electricity consumption to employment for the industries were calculated from data in the Census of Manufactures.

${ }^{11}$ Due to restrictions on the use of gas by industrial customers, it can be shown that under general conditions for industrial users the shadow price of gas at the margin equals the price of fuel oil. Moreover, the high degree of substitutability among fuel oils in many processes suggests that the prices of these goods will continue to move together in the future. 
peak demand price and income elasticities. ${ }^{12}$ Without such estimates, kilowatt hour demand elasticities give no information as to the effect of price and income changes on load factors. However, once both kw peak and kwh demand elasticities are obtained, the behavior of load factors can be inferred.

If the system $\mathrm{kw}$ peak income elasticity is larger than the system kwh demand income elasticity, as we find, then growth in income will bring about a large increase in required $\mathrm{kw}$ capacity relative to the actual $\mathrm{kwh}$ demand, and the load factor will decline. Similarly, if system peak price elasticity is smaller in magnitude than the system kwh demand price elasticity, as we find, then increased real electricity prices will lead to a load factor decline.

We jointly estimate the structure of VEPCO's monthly kilowatt peak demand for each of the summer months. (VEPCO's annual peak has occurred in the summer over the entire sample period.) The monthly peaks are assumed to follow a distributed lag pattern reflecting the lags in the demand responses outlined in sections II and III.

$$
\ln M_{t}=\Sigma \beta_{j} Z_{j t}+\lambda_{1} \ln M_{t-1}+\lambda_{2} \ln M_{t-12}
$$

where $\lambda_{1}$ and $\lambda_{2}$, and the $\beta_{j}$ are parameters, $M$ is monthly peak kilowatts, and the $Z_{j}$ are the determinants of peak kilowatt demand. Again, $M_{t-1}$ captures the usual short run lags in behavioral response, while $M_{t-12}$ accounts for both seasonal factors and the dynamic adjustment of the season-specific capital stocks.

Since a utility's peak demand involves demands by all customer classes, the $Z_{j}$ should include all the variables of the three kilowatt hour demand equations. Unfortunately, many of these variables are highly collinear over the sample period and some accommodation is necessary. The marginal energy prices from the commercial and industrial kilowatt hour demand models are summed, together with similar constructions based on the residential price structure, to form two price variables. A marginal demand price is formed by summing the marginal demand prices from the commercial and indus-

\footnotetext{
12 There have been some analyses of time of day $\mathrm{kwh}$ elasticities, such as Cargill and Meyer (1971) and Atkinson (1977). Uri (1977) offers an analysis of system kw peak using monthly data, as we do here, but he focuses on forecasting and does not report elasticities. Noneconomic analyses of peak demand forecasts are summarized by Gupta (1969).
}

trial kilowatt hour demand models. Both the electric-intensity-industrial-activity index and total taxable income are included to reflect economic activity and income. The price of the most widely used alternative fuel, \#6 residual oil, is included. (In the residential sector \#2 heating oil is the most widely used alternative, but multicollinearity precluded including both prices. Other fuel prices were also highly collinear with the oil prices.) One average temperature variable is included as well.

\section{Data}

Monthly kilowatt hour sales, from January 1958 to December 1973, by customer class, by each of nine billing districts were obtained from marketing reports provided by VEPCO. The company also provided summer month $\mathrm{kw}$ peak demands for 1960 through 1973 and schedules of prices for each customer class (inclusive of fuel adjustment costs) over the sample period. Data beyond 1973 were not used because the company reorganized its billing districts, destroying the comparability, at the billing district level, of earlier and subsequent data bases.

Demographic data were gathered from the Tayloe Murphy Institute for each of the state's counties and independent cities. Taxable income by county and city for the sample period was provided by the Virginia Department of Taxation. Taxable income is used in lieu of gross income, which was not available on a county or city basis. Since the billing district boundaries do not coincide with city and county lines, it was necessary to transcribe a map of districts onto a map showing county and city lines. Since each billing district's boundaries are in the less populous parts of a legal jurisdiction, reasonable approximations to the true population and income data were obtained by matching the billing districts to the jurisdictions they embraced. ${ }^{13}$

Neither income nor population data were available on a monthly basis, so the annual data were interpolated to approximate the true data. Population data were interpolated linearly, while the income data were assumed to follow the same path as employment, for which monthly observa-

\footnotetext{
${ }^{13}$ Since the boundaries of the billing districts are in rural areas or along jurisdictional boundaries, it was not difficult to ascertain to which billing district a city or county contributed the bulk of its population and income.
} 
tions were available from the Virginia State Employment Commission.

The actual income variable used in the residential regressions is not taxable income interpolated, but rather a measure of permanent income. Annual gross state income was regressed against annual state taxable income over the period 1941 to 1973 . This relationship was used to estimate annual gross income from annual taxable income on a county and city basis. These annual estimates were then coupled with Friedman's (1957) weights to form a permanent income variable (a procedure drawn from the work of Fisher and Kaysen (1962)). It is the permanent income variable that is interpolated and utilized in the residential sector regressions. This measure of income is used so that the price and income elasticities estimated in the residential sector are comparable, both capturing the influence of past values of prices and income; multicollinearity among present and lagged prices made such an outcome unavoidable for price elasticities. ${ }^{14}$

The temperature data were obtained from the Environmental Data Service of the U.S. Department of Commerce. The data were average monthly temperatures for six climatic divisions of the state. Some VEPCO billing districts fall into a single climatic division, others into two. In the residential regressions, the single temperature variable was used in the former case, and the temperature variables from both divisions were used in the latter case. In the industrial and commercial regressions an average of the two temperature variables was used when the billing district fell in two climatic divisions.

The fuel oil prices are an average of the prices for Charlotte, North Carolina and Washington, D.C. These prices were provided by Foster Associates. All nominal variables in the study are deflated by the Consumer Price Index to express them in real terms.

\section{Billing District Demands}

Our data permit differentiation among VEPCO's nine Virginia billing districts, and $F$-tests

\footnotetext{
14 We might also have constructed permanent price variables, using weights from earlier studies. However, the high degree of collinearity among lagged price variables implies the choice makes little difference. Moreover, since most studies that account for dynamics do not differentiate between lagged price responses and lagged adjustments in appliance stocks, it is not clear what weight one could select.
}

indicate that the demand parameters are not homogeneous across these districts. This section summarizes the seasonal demand regressions for each customer class in each billing district, ${ }^{15}$ and presents the regression results for the system (summer) kw peak demand. Of course, for most policy purposes it is the system-wide price and income elasticities that are of interest, and in the next section we present the price and income elasticity estimates implied by the estimated district parameters.

The variation in demand parameters across billing districts is not surprising. Variations in rural/urban composition, industrial mix, the ratio of single family to multiple family units, and the like will alter the pattern of electricity demand. Also, to the extent the log-linear specification is an approximation, regional differences in income, weather, etc. imply that the true demand structures are being estimated about different points across the regions.

For commercial and industrial users, we have monthly data and we use this to differentiate among four seasons: summer, fall, winter, and spring. ${ }^{16}$ Residential customers are generally billed on a bimonthly basis, with one group of customers billed in odd months (January, March, etc.) and another billed in even months (February, April, etc.). $F$-tests indicate that these residential billing groups are not homogeneous, ${ }^{17}$ so separate demand equations are estimated for each billing group in each district. The restriction to bimonthly data limited us to only two seasons, hot and cold. ${ }^{18}$

The lack of homogeneity among billing groups is somewhat surprising. One likely explanation is that meters are read in half the billing district in

${ }^{15}$ Due to missing data, 2 billing districts were not examined for the Industrial Fall demand, and 1 was not examined for the Industrial Spring demand. The missing elasticities were estimated as the aggregate elasticities for the remaining observations.

${ }^{16}$ Summer is June, July, and August; Fall is September, October, and November; Winter is December, January, and February; and Spring is March, April, and May.

${ }^{17}$ In two of its Virginia billing districts, VEPCO delivers natural gas as well as electricity. Since in these districts the gas meters are read monthly, the electricity customers also receive monthly bills. In these two districts, the odd months and even months do appear homogeneous, as one would hope, but separate regressions were still maintained for simplicity.

${ }^{18}$ For customers billed in odd months, cold is October through March and hot is April through September. For customers billed in even months, cold is November through April and hot is May through October. 
one month, and in the remaining area the next month. The geographic and demographic dispersion between the two areas accounts for the lack of homogeneity. This explanation is consistent with the finding that in the two districts in which residential billing is monthly, homogeneity between odd and even months was not rejected.

The residential demands, of the form given in equation (1), were estimated by an iterative least squares procedure to obtain unique parameter estimates. ${ }^{19}$ In every instance the estimated value of the speed of adjustment converged to unity. While this result is surprising, it is consistent with the finding that the estimated speed of adjustment in system peak kw demand (which is a mix of commercial, residential and industrial responses) is faster than the commercial and in-

\footnotetext{
19 The iterative procedure selected a value for $\phi$, performed OLS conditional on this value, then used values of $\phi$ near, but on opposite sides of, the first $\phi$ to seek a lower sum of squared residuals. A new $\phi$ was then chosen in the new direction and the process repeated until the $\phi$ converged. $\phi$ was restricted a priori to the zero and one interval.
}

dustrial adjustments. ${ }^{20}$ Conditional upon the result that $\phi=1$, the Cochrane-Orcutt procedure was applied to demand functions of the form given in equation $\left(1^{\prime}\right)$ to correct for apparent first order serial correlation. The mean estimated coefficients of $\left(1^{\prime}\right)$, by season, across billing districts, and the standard deviations of these coefficients across billing districts, are presented in table 1; all the variables are measured in real terms.

In each of the eighteen residential regressions we tested the hypothesis that the inframarginal price variable has a coefficient equal in magnitude, but opposite in sign, to the income coefficient. In fourteen cases we fail to reject the null hypothesis $(\alpha=.05) .{ }^{21} \mathrm{We}$ also tested the per

20 One possible explanation of the rapid adjustments is that the sample period was a stable one in which income growth and price changes could well have been correctly anticipated by households. There is no evidence here that the adjustment to large, unanticipated shocks, such as VEPCO's $37 \%$ increase in real electricity prices in 1975, is instantaneous.

21 These failures to reject are not very conclusive since

Table 1.-Mean Estimated Residential Sector Demand Coefficients by Season, by District and Their Standard Deviations across Districts

\begin{tabular}{|c|c|c|c|c|}
\hline \multirow[b]{3}{*}{ Variable } & \multicolumn{4}{|c|}{ Coefficients } \\
\hline & \multicolumn{2}{|c|}{ Cold } & \multicolumn{2}{|c|}{ Hot } \\
\hline & Group I & Group II & Group I & Group II \\
\hline Per capita kilowatt hours demanded in bimonth & \multicolumn{4}{|c|}{ (dependent variable) } \\
\hline Dummy for 1 st bimonth in season & -7.25 & 1.21 & -7.33 & -3.51 \\
\hline Dummy for 2 nd bimonth in season & -7.14 & 1.12 & -7.33 & -3.34 \\
\hline Dummy for 3rd bimonth in season & -7.38 & 1.07 & -7.20 & -3.40 \\
\hline Sum of first 5 block prices multiplied by the block lengths, & & & & \\
\hline lagged one month $\left(P_{1}\right)$ & $\begin{array}{c}-0.22 \\
(0.32)\end{array}$ & $\begin{array}{l}0.13 \\
(0.46)\end{array}$ & $\begin{array}{c}-0.04 \\
(0.29)\end{array}$ & $\begin{array}{c}0.54 \\
(0.27)\end{array}$ \\
\hline Sum of 6 th and 7 th prices, lagged one month $\left(P_{2}\right)$ & $\begin{array}{l}-1.07 \\
(1.33)\end{array}$ & $\begin{array}{r}-1.89 \\
(1.13)\end{array}$ & $\begin{array}{l}-1.10 \\
(1.01)\end{array}$ & $\begin{array}{c}-1.51 \\
(1.43)\end{array}$ \\
\hline Sum of 8 th and 9 th prices, lagged one month $\left(P_{3}\right)$ & $\begin{array}{c}-0.02 \\
(0.08)\end{array}$ & $\begin{array}{c}0.09 \\
(0.08)\end{array}$ & $\begin{array}{c}0.04 \\
(0.07)\end{array}$ & $\begin{array}{c}-0.08 \\
(0.07)\end{array}$ \\
\hline Average of $P_{1}$ in this season, lagged one year & $\begin{array}{r}-0.57 \\
(0.43)\end{array}$ & $\begin{array}{c}-0.63 \\
(0.39)\end{array}$ & $\begin{array}{r}-0.10 \\
(0.42)\end{array}$ & $\begin{array}{l}-0.35 \\
(0.68)\end{array}$ \\
\hline Average of $P_{2}$ in this season, lagged one year & $\begin{array}{l}1.75 \\
(0.91)\end{array}$ & $\begin{array}{c}0.81 \\
(1.19)\end{array}$ & $\begin{array}{l}1.48 \\
(1.65)\end{array}$ & $\begin{array}{c}0.72 \\
(2.24)\end{array}$ \\
\hline Average of $P_{3}$ in this season, lagged one year & $\begin{array}{r}-0.04 \\
(0.11)\end{array}$ & $\begin{array}{c}-0.28 \\
(0.16)\end{array}$ & $\begin{array}{r}-0.10 \\
(0.36)\end{array}$ & $\begin{array}{l}-0.15 \\
(0.19)\end{array}$ \\
\hline Per capita permanent income for this year $(Y)$ & $\begin{array}{c}0.71 \\
(0.86)\end{array}$ & $\begin{array}{c}-0.29 \\
(1.11)\end{array}$ & $\begin{array}{c}0.53 \\
(0.71)\end{array}$ & $\begin{array}{c}0.76 \\
(0.97)\end{array}$ \\
\hline Average of $Y$ in this season, lagged one year & $\begin{array}{c}0.17 \\
(0.73)\end{array}$ & $\begin{array}{c}0.61 \\
(0.96)\end{array}$ & $\begin{array}{c}0.33 \\
(0.61)\end{array}$ & $\begin{array}{c}-0.17 \\
(0.93)\end{array}$ \\
\hline 1st temperature & $\begin{array}{c}0.06 \\
(0.47)\end{array}$ & $\begin{array}{c}-0.08 \\
(0.12)\end{array}$ & $\begin{array}{c}0.85 \\
(0.97)\end{array}$ & $\begin{array}{c}-0.28 \\
(1.06)\end{array}$ \\
\hline 2nd temperature & $\begin{array}{c}-0.41 \\
(0.74)\end{array}$ & $\begin{array}{c}-0.03 \\
(0.18)\end{array}$ & $\begin{array}{r}-1.10 \\
(1.14)\end{array}$ & $\begin{array}{c}1.15 \\
(1.70)\end{array}$ \\
\hline Price of $\# 2$ heating oil & $\begin{array}{c}-0.19 \\
(0.20)\end{array}$ & $\begin{array}{c}-0.14 \\
(0.28)\end{array}$ & $\begin{array}{c}-1.12 \\
(0.45)\end{array}$ & $\begin{array}{c}-0.41 \\
(1.08)\end{array}$ \\
\hline$R^{2}$ & $\begin{array}{c}0.99 \\
(0.006)\end{array}$ & $\begin{array}{c}0.99 \\
(0.002)\end{array}$ & $\begin{array}{c}0.99 \\
(0.006)\end{array}$ & $\begin{array}{c}0.99 \\
(0.002)\end{array}$ \\
\hline
\end{tabular}

Note: Logs of above used as variables. Figures in parentheses are not standard errors, but standard deviations of estimates across billing districts. 
capita formulation for income and kwh demand; in fifteen of eighteen cases we could not reject the constraint $(\alpha=.05)$. Also, in fourteen of eighteen cases we reject $(\alpha=.05)$ the null hypothesis that all price coefficients are zero. Finally, in ten of eighteen cases, we fail to reject $(\alpha=.05)$ the null hypothesis that the coefficient of fuel oil is zero, and in the remaining cases the coefficients are of the wrong sign. ${ }^{22}$

The commercial and industrial demands (of the form given in equation (2)) were estimated by ordinary least squares. Given the finding about inframarginal prices in the residential sector, the average price of elasticity is assumed to have a coefficient equal in magnitude but opposite in sign to the income variable. ${ }^{23}$ Durbin-Watson

they derive largely from the large standard errors on the price coefficients arising from the high degree of multicollinearity among all the price variables; moreover, as indicated in footnote 6 , this test is, at best, only an approximation to a true test.

22 The use of the price of natural gas did not alter these results about the importance of alternative fuel prices to the residential demand for electricity.

${ }^{23}$ It has been pointed out to us that the log of the average price of electricity should not be subtracted from the log of income, as we have done. First, it is inframarginal expenditure, not average price, whose effect is similar to income. Second, an average price variable is negatively correlated with the disturbance term. Fortunately, the biases introduced by what amounts to a mismeasurement of income are not likely to be large. Average price is quite small relative to income, and its variance is small relative to that of income. Moreover, the bulk of this small bias will be absorbed as an tests for serial correlation indicated no need for corrections. Tables 2 and 3 present the mean estimated coefficients, by season, of the commercial and industrial demands across billing districts, and the standard deviations of those estimated coefficients across districts. ${ }^{24}$ All the variables are measured in real terms.

increase in the expected value of the marginal price coefficients, since the marginal prices are highly positively correlated with average price; correction for this part of the bias would only reinforce our conclusions. The income coefficient is likely to be biased upwards only slightly and almost certainly not enough to reverse our conclusions. Unfortunately, the considerable cost of redoing all 72 commercial and industrial estimations makes such small corrections uneconomical.

${ }^{24}$ The observed variation in estimated coefficients across billing districts and billing groups could arise from two sources. First are differences in the actual coefficients that are being estimated, and second are the sampling errors inherent in estimation. Comparisons of the sums of squared residuals from pooled and disaggregated regressions ( $F$-tests) indicate that the latter source is not sufficient to explain the observed variation by itself, so we conclude that there are coefficient differences across districts and across billing groups. Examination of the observed differences in estimated coefficients and their estimated standard errors suggests that these differences are not only statistically significant, but appreciable as well. The standard deviations of estimated coefficients across districts are not reported for purposes of statistical inference, but rather as summary statistics for the distribution of estimated coefficients across regressions. Statistical inference is postponed to section VII. Readers who wish to purchase xeroxed summaries of the individual regression results, with a key to variable names, should contact Michael Murray.

Table 2.-Mean Estimated Commercial Sector Demand Coefficients by Season, by District and Their Standard Deviations across Districts

\begin{tabular}{|c|c|c|c|c|}
\hline \multirow[b]{2}{*}{ Variable } & \multicolumn{4}{|c|}{ Coefficients } \\
\hline & Fall & Winter & Spring & Summer \\
\hline Log of kilowatt hours demanded (kwh) & \multicolumn{4}{|c|}{ (dependent variable) } \\
\hline Sum of logs of two marginal energy charges & $\begin{array}{c}0.11 \\
(0.18)\end{array}$ & $\begin{array}{c}0.04 \\
(0.03)\end{array}$ & $\begin{array}{c}-0.02 \\
(0.12)\end{array}$ & $\begin{array}{c}-0.04 \\
(0.03)\end{array}$ \\
\hline Log of marginal demand charge & $\begin{array}{c}0.02 \\
(0.05)\end{array}$ & $\begin{array}{r}0.007 \\
(0.01)\end{array}$ & $\begin{array}{c}-0.005 \\
(0.03)\end{array}$ & $\begin{array}{c}-0.02 \\
(0.01)\end{array}$ \\
\hline $\begin{array}{l}\text { Difference between logs of income and averag } \\
\text { price }\end{array}$ & $\begin{array}{c}0.42 \\
(0.36)\end{array}$ & $\begin{array}{c}0.27 \\
(0.13)\end{array}$ & $\begin{array}{c}0.003 \\
(0.002)\end{array}$ & $\begin{array}{c}0.002 \\
(0.009)\end{array}$ \\
\hline Log of average temperature & $\begin{array}{c}-0.001 \\
(0.005)\end{array}$ & $\begin{array}{l}0.003 \\
(0.003)\end{array}$ & $\begin{array}{l}0.001 \\
(0.0006)\end{array}$ & $\begin{array}{l}0.008 \\
(0.004)\end{array}$ \\
\hline Log of kwh lagged one month & $\begin{array}{c}0.51 \\
(0.27)\end{array}$ & $\begin{array}{l}0.34 \\
(0.18)\end{array}$ & $\begin{array}{c}0.63 \\
(0.22)\end{array}$ & $\begin{array}{l}0.49 \\
(0.15)\end{array}$ \\
\hline Log of kwh lagged one year & $\begin{array}{c}0.07 \\
(0.20)\end{array}$ & $\begin{array}{c}0.28 \\
(0.25)\end{array}$ & $\begin{array}{c}0.34 \\
(0.18)\end{array}$ & $\begin{array}{c}0.43 \\
(0.17)\end{array}$ \\
\hline Log of price of \#6 residual oil & - & $\begin{array}{c}0.22 \\
(0.18)\end{array}$ & - & - \\
\hline Constant & $\begin{array}{l}4.35 \\
(2.39)\end{array}$ & $\begin{array}{l}2.75 \\
(2.17)\end{array}$ & $\begin{array}{c}0.43 \\
(0.56)\end{array}$ & $\begin{array}{c}0.47 \\
(1.60)\end{array}$ \\
\hline$R^{2}$ & $\begin{array}{c}0.97 \\
(0.04)\end{array}$ & $\begin{array}{c}0.94 \\
(0.08)\end{array}$ & $\begin{array}{c}0.96 \\
(0.04)\end{array}$ & $\begin{array}{c}0.91 \\
(0.19)\end{array}$ \\
\hline
\end{tabular}

Note: Figures in parentheses are not standard errors, but standard deviations of estimates across billing districts. 
Table 3.-Mean Estimated Industrial Sector Demand Coefficients by Season, by District and Their STANDARD DEVIaTIONS ACROSS DISTRICTS

\begin{tabular}{|c|c|c|c|c|}
\hline \multirow[b]{2}{*}{ Variable } & \multicolumn{4}{|c|}{ Coefficients } \\
\hline & Fall & Winter & Spring & Summer \\
\hline Log of kilowatt hours demanded (kwh) & \multicolumn{4}{|c|}{ (dependent variable) } \\
\hline Sum of logs of two marginal energy charges & $\begin{array}{l}-0.08 \\
(0.94)\end{array}$ & $\begin{array}{c}-0.27 \\
(0.42)\end{array}$ & $\begin{array}{r}-0.37 \\
(1.3)\end{array}$ & $\begin{array}{c}-0.08 \\
(0.50)\end{array}$ \\
\hline Sum of logs of two marginal demand charges & $\begin{array}{c}-0.96 \\
(1.61)\end{array}$ & $\begin{array}{c}-0.78 \\
(1.23)\end{array}$ & $\begin{array}{c}-0.75 \\
(2.35)\end{array}$ & $\begin{array}{c}-0.28 \\
(1.88)\end{array}$ \\
\hline $\begin{array}{l}\text { Difference between logs of activity index and average } \\
\text { electricity price }\end{array}$ & $\begin{array}{c}0.56 \\
(0.44)\end{array}$ & $\begin{array}{c}0.37 \\
(0.44)\end{array}$ & $\begin{array}{c}0.92 \\
(0.89)\end{array}$ & $\begin{array}{c}0.33 \\
(0.41)\end{array}$ \\
\hline Log of average temperature & $\begin{array}{r}-0.0003 \\
(0.004)\end{array}$ & $\begin{array}{c}-0.002 \\
(0.004)\end{array}$ & $\begin{array}{r}-0.004 \\
(0.008)\end{array}$ & $\begin{array}{c}-0.002 \\
(0.004)\end{array}$ \\
\hline Log of $k w h$ lagged one month & $\begin{array}{c}0.12 \\
(0.27)\end{array}$ & $\begin{array}{l}0.10 \\
(0.25)\end{array}$ & $\begin{array}{l}-0.07 \\
(0.35)\end{array}$ & $\begin{array}{l}0.10 \\
(0.27)\end{array}$ \\
\hline Log of kwh lagged one year & $\begin{array}{c}0.14 \\
(0.53)\end{array}$ & $\begin{array}{l}0.13 \\
(0.41)\end{array}$ & $\begin{array}{c}-0.37 \\
(0.45)\end{array}$ & $\begin{array}{l}0.18 \\
(0.34)\end{array}$ \\
\hline Log of price of \#6 residual oil & $\begin{array}{c}0.86 \\
(1.43)\end{array}$ & $\begin{array}{c}0.04 \\
(0.42)\end{array}$ & $\begin{array}{c}0.11 \\
(1.22)\end{array}$ & $\begin{array}{c}0.04 \\
(0.69)\end{array}$ \\
\hline Constant & $\begin{array}{c}6.32 \\
(10.05)\end{array}$ & $\begin{array}{c}8.72 \\
(7.75)\end{array}$ & $\begin{array}{c}14.35 \\
(15.28)\end{array}$ & $\begin{array}{c}6.82 \\
(8.32)\end{array}$ \\
\hline$R^{2}$ & $\begin{array}{c}0.94 \\
(0.06)\end{array}$ & $\begin{array}{c}0.82 \\
(0.17)\end{array}$ & $\begin{array}{c}0.89 \\
(0.11)\end{array}$ & $\begin{array}{c}0.89 \\
(0.05)\end{array}$ \\
\hline
\end{tabular}

Note: Figures in parentheses are not standard errors, but standard deviations of estimates across billing districts.

The most striking feature of tables $1-3$ is the wide variation of coefficients across districts; in general these differences are statistically significant. The lesson to be learned from this is that regulatory bodies may have to consider regional differences in the impact of proposed rate changes on customers within a company's service area and that, when reviewing utility plans to increase transmission and generating facilities, regulators may have to give special attention to the geographic distribution of such facilities since uniform income and price changes may generate uneven geographic demand changes.

Since VEPCO has long been a summer peaking company, and since this pattern does not appear to be changing, the structure of system-wide $\mathrm{kw}$ peak demands was estimated only for the summer months. Ordinary least squares was applied to a demand equation of the form given in equation (3); all the variables are measured in real terms. Tests indicated no problems of serial correlation. The estimated coefficients from this regression, and their $t$-statistics, are presented in table 4 . Some may be surprised to see that the kw peak is less responsive to demand charges than to energy charges. This apparent anomaly disappears when one realizes that residential customers, and even some small commercial and industrial users, do not have demand meters, and pay only energy charges.
Tabie 4.-Estimated Peak Demand Coefficients and THEIR $t$-STATISTICS

\begin{tabular}{lr}
\hline \multicolumn{1}{c}{ Variable } & \multicolumn{1}{c}{ Coefficients } \\
\hline $\begin{array}{l}\text { Log of system's monthly peak } \\
\text { kilowatts (kw) }\end{array}$ & (dependent variable) \\
Sum of the logs of six marginal & \\
$\quad$ energy charges & $-0.05(2.30)$ \\
Sum of the logs of three marginal & \\
demand charges & $-0.02(2.40)$ \\
Log of taxable income & $0.64(3.42)$ \\
Log of electric-intensity-indus- & \\
trial-activity index & $0.26(1.28)$ \\
Log of kw lagged one month & $0.16(3.02)$ \\
Log of kw lagged one year & $0.13(1.23)$ \\
Log of the price of \# 6 residual oil & $0.07(0.94)$ \\
Log of constant & $-5.14(8.54)$ \\
\hline
\end{tabular}

Note: Figures in parentheses are $t$-statistics.

\section{Price and Income Elasticities}

In 1973 residential customers accounted for $44 \%$ of VEPCO's kwh demanded; commercial customers registered $33 \%$ of VEPCO's kwh demanded; and industrial users demanded the remaining $23 \%$ of total $\mathrm{kwh}$. The system-wide price and income elasticities for VEPCO are weighted averages of the separate elasticities of each customer class in each billing district, in which the weights are these relative shares of total kwh demanded. Since the estimated price and income elasticities are short run elasticities, it is neces- 
sary to use the estimated dynamic coefficients to produce long run elasticity estimates. ${ }^{25}$

The disaggregated elasticities can be estimated from the customer-class, billing-district regression coefficients. In the residential sector, the kwh demand elasticity with respect to a uniform increase in all block prices is the sum of each of the six coefficients of the price variables; the residential income elasticity of demand is the sum of the coefficients of the two income variables. In the commercial and industrial sectors, the kwh demand elasticity with respect to the two marginal kwh price measures is twice the (common) coefficient of the kwh price variable; the kwh demand elasticities with respect to the one $\mathrm{kw}$ price variable in the commercial sector, and with respect to the two $\mathrm{kw}$ price variables in the industrial sector, are the coefficient of the $\mathrm{kw}$ price variable(s), and twice that coefficient, respectively. The income elasticity in the commercial sector is simply the coefficient of the income variable; in the industrial sector it is necessary to assume that changes in income generate equiproportionate changes in employment across industries if the coefficient of the electric-intensity-industrial-activity index is to be interpreted as an income elasticity. For kw peak demand, the price elasticity of demand with respect to a uniform change in all six marginal price variables is six times their common coefficient; the price elasticity of demand with respect to a uniform change in all three marginal demand price variables is thrice their common coefficient; finally, the income elasticity of $\mathrm{kw}$ peak demand is the sum of the coefficients of the income and electric-intensity-industrial-activity index variables, under the assumption mentioned above.

Under the assumption of normally distributed disturbances in the regressions, each of the disaggregated elasticity estimators is normally distributed, and, therefore, so would be the system elasticity estimators based upon them. However, these normally distributed estimators are not necessarily the most efficient estimators available because they do not incorporate our prior beliefs about the signs of the coefficients. Incorporation of these prior beliefs into the estimation

25 It should be recalled that the short run-long run distinction is used to refer to the dynamic adjustments in capital stocks and utilization rates. Multicollinearity among the price variables prevents differentiation of responses to current and lagged prices. process is especially important when the parameters to be estimated are small relative to both zero and to the variances of the normally distributed estimators, since it is in these instances that a large portion of the probability masses of the estimators' density functions fall on the intuitively wrong side of zero. ${ }^{26}$

The estimated variances of our income elasticity estimators are small enough relative to the estimated elasticities that we need not concern ourselves with the inefficiency of the regression coefficient estimators, but our price elasticity estimators have sufficient variance to make an alternative estimation procedure worthwhile. ${ }^{27}$

In the case of price elasticities, we define a truncated estimator, $x_{\tau}$, in terms of the normally distributed estimator, $x$.

$$
x_{\tau}=\min (x, 0) \text {. }
$$

These truncated estimators are attractive because they have smaller variances than the normally distributed estimators, but they are also biased. Fortunately, it is not difficult to put upper and lower bounds on both the variance and bias of the truncated estimator, expressed in terms of the variance of the normally distributed estimators. In a special case of interest, in which the true parameter equals zero, we can state the exact variance and bias of $x_{\tau}$ in terms of the variance of $x$.

The cumulative distribution function for the truncated estimator, $F\left(x_{\tau}\right)$, is

$$
\begin{array}{rlr}
F\left(x_{\tau}\right)= & (\sigma \sqrt{2 \pi})^{-1} \\
& \times \int_{-\infty}^{x_{\tau}} \exp \left[-\left(x_{\tau}-\beta\right)^{2} / 2 \sigma^{2}\right] d x_{\tau}, & x_{\tau}<0 \\
F\left(x_{\tau}\right)= & \operatorname{Pr}(x \geq 0)+\lim _{x \rightarrow-0} F(x), & x_{\tau}=0
\end{array}
$$

${ }^{26}$ For example, if the true elasticity is zero, half of the coefficients estimated (in the long run) will be positive. In our regressions $44 \%$ of the price elasticities were of the wrong sign; if all the elasticities were zero, the probability of obtaining as few as $44 \%$ positive is only $6 \%$.

27 Although the estimator developed below utilizes prior information, it is decidedly non-Bayesian in spirit. The parameter to be estimated is just that, and not a random variable; the prior information is not a distribution for a random variable, but rather a simple non-positivity restriction. The chief attractions of the estimator are its simplicity and efficiency; the chief drawback is its bounded, but otherwise unknown bias. A Bayesian estimator would be more complicated (involving several truncated distributions), require more a priori assumptions (the prior density over nonpositive values), and would still be biased. We are grateful to T. W. Epps for discussions about our truncated estimator. 


$$
F\left(x_{\tau}\right)=1,
$$

Thus, the expected value of $x_{r}$ is

$$
\begin{aligned}
b & =E\left(x_{\tau}\right)=(\sigma \sqrt{2 \pi})^{-1} \\
& \times \int_{-\infty}^{0}(x) \exp \left[-\left(x_{\tau}-\beta\right)^{2} / 2 \sigma^{2}\right] d x,
\end{aligned}
$$

The bias in this is $E\left(x_{\tau}\right)-E(x)$, or

$$
-(\sigma \sqrt{2 \pi})^{-1} \int_{0}^{\infty}(x) \exp \left[-\left(x_{r}-\beta\right)^{2} / 2 \sigma^{2}\right] d x,
$$

which reaches a maximum in magnitude $(-\sigma / \sqrt{2 \pi})$ at $\beta=0$, and approaches zero as $\beta$ approaches $-\infty$.

The variance of the truncated estimator when $\beta=0$ is

$$
\begin{aligned}
s^{2}= & (0-b)^{2} \cdot 1 / 2+(\sigma \sqrt{2 \pi})^{-1} \\
& \times \int_{-\infty}^{0}(x-b)^{2} \exp \left[-x^{2} / 2 \sigma^{2}\right] d x \\
= & b^{2} / 2+(\sigma \sqrt{2 \pi})^{-1} \\
& \times\left[\int_{-\infty}^{0} x^{2} \exp \left[-x^{2} / 2 \sigma^{2}\right] d x\right. \\
& \quad-\int_{-\infty}^{0} 2 b x \exp \left[-x^{2} / 2 \sigma^{2}\right] \\
& \left.\quad+b^{2} \int_{-\infty}^{0} \exp \left[-x^{2} / 2 \sigma^{2}\right] d x\right] \\
= & b^{2} / 2+\sigma^{2} / 2-2 b^{2}+b^{2} / 2 \\
= & \sigma^{2} / 2-b^{2}=.341 \sigma^{2} .
\end{aligned}
$$

That $s^{2}$ attains a minimum for $\beta \leq 0$ at $\beta=0$ can be seen by considering the case in which $\beta>0$; the result exceeds $s^{2}$ at $\beta=0$ by a positive amount.

The chief attraction to truncating the normally distributed price elasticity estimators for each billing district and customer class is that when we form the weighted averages of such estimators (using from nine to seventy terms in the sums) it is reasonable to appeal to the central limit theorem and to treat the system-wide elasticities as (approximately) normally distributed.

For the primary null hypothesis of interest, that the elasticities are zero, the above formulae for bias and variance hold exactly, and asymptotically valid test statistics can be formed in the fashion of the usual $t$-statistic. Tests of other hypotheses are generally less conclusive since we can examine results only at the bounds of the bias $(-\sigma / 2 \pi, 0)$ and of the variance $\left(.341 \sigma^{2}, \sigma^{2}\right)$.
When corrected for maximum bias, the truncated estimators of system elasticities are not much different in magnitude than the untruncated estimators. The primary gain from truncation is the reduction in estimated standard error of more than $40 \%$. Since the untruncated point estimates of system price elasticities do not differ appreciably from the maximally corrected truncated point estimates, the untruncated estimates are not reported.

Tables 5, 6, and 7 present the estimated system-wide income, own price, and cross price elasticities for each customer class in each season, for the total system, and for kw peak demand. Both short run and long run elasticity estimates are reported, but the former are considerably more reliable than the latter. In each commercial or industrial regression, the estimated long run elasticity is the short run elasticity divided by one minus the sum of the lag coefficients. In general, the standard errors on the lag coefficients were relatively large. Moreover, in a substantial number of cases, the sum of the lag coefficients is negative or exceeds unity, implying the dynamic system is not monotonically stable. In the instances in which the sum of the lags is negative, the sum is treated as if it were zero, thereby equating long run and short run responses. In the instances in which the sum of the lag coefficients is in excess of one, the long run response is assumed to be equal to the average long run response for that class of customers in that season. In one other instance, the sum of the lag coefficients is very nearly one, but has a large standard error; to keep this case's long run elasticities (on the order of 150) from dominating the long run results, this case was treated like those in which the sum of the lag coefficients exceeds one.

The estimates of the income elasticities seem the most reliable; the standard errors of the estimates are generally small relative to the estimated coefficients, even at the billing district level. For the system-wide responses, only the commercial spring and summer income elasticities are insignificant at the 0.05 significance level. While elasticities vary appreciably across customer classes, and across seasons within customer classes, there is little cross seasonal variation in income elasticity for the system as a whole; thus growing incomes will tend to increase the absolute gap between summer and 
Table 5.-System-Wide Income and Industrial Activity Index Elasticities

\begin{tabular}{|c|c|c|c|c|c|}
\hline & \multicolumn{2}{|c|}{ Cold } & \multicolumn{2}{|c|}{ Hot } & \multirow{3}{*}{$\begin{array}{c}\text { Annual } \\
0.69 \\
(0.05)\end{array}$} \\
\hline \multirow[t]{2}{*}{ Residential } & & & & & \\
\hline & Fall & Winter & Spring & Summer & \\
\hline \multicolumn{6}{|l|}{ Commercial } \\
\hline short run & $\begin{array}{c}0.60 \\
(0.11)\end{array}$ & $\begin{array}{c}0.27 \\
(0.05)\end{array}$ & $\begin{array}{c}0.001 \\
(0.004)\end{array}$ & $\begin{array}{c}0.001 \\
(0.003)\end{array}$ & $\begin{array}{c}0.02 \\
(0.03)\end{array}$ \\
\hline long run & 1.90 & 0.82 & 0.001 & 0.001 & 0.70 \\
\hline \multicolumn{6}{|l|}{ Industrial } \\
\hline short run & $\begin{array}{c}0.62 \\
(0.17)\end{array}$ & $\begin{array}{c}0.58 \\
(0.13)\end{array}$ & $\begin{array}{c}1.25 \\
(0.23)\end{array}$ & $\begin{array}{c}0.86 \\
(0.12)\end{array}$ & $\begin{array}{c}0.82 \\
(0.08)\end{array}$ \\
\hline long run & 1.07 & 0.74 & 1.52 & 1.11 & 1.11 \\
\hline \multicolumn{6}{|l|}{ Total system } \\
\hline short run & - & $\begin{array}{c}0.48 \\
(0.06)\end{array}$ & - & $\begin{array}{c}0.54 \\
(0.03)\end{array}$ & $\begin{array}{c}0.52 \\
(0.03)\end{array}$ \\
\hline long run & - & 0.68 & - & 0.59 & 0.79 \\
\hline \multicolumn{6}{|l|}{ System kw peak } \\
\hline short run & - & - & - & 0.90 & - \\
\hline long run & - & - & - & 1.27 & - \\
\hline
\end{tabular}

winter demands, but will not affect the relative difference. However, the income elasticity of $\mathrm{kw}$ peak demand (and, therefore, of kwh capacity) is markedly larger than the actual kwh demand elasticity; therefore, if incomes grow, VEPCO will tend to experience deteriorating load factors.

Table 6.-Ranges a for System-Wide OWn Price Elasticities

\begin{tabular}{|c|c|c|c|c|c|}
\hline & \multicolumn{2}{|c|}{ Cold } & \multicolumn{2}{|c|}{ Hot } & Annual \\
\hline \multirow[t]{2}{*}{ Residential } & \multicolumn{2}{|c|}{$\begin{array}{c}-1.43,-0.95 \\
(0.15)\end{array}$} & \multicolumn{2}{|c|}{$\begin{array}{c}-0.60,-0.26 \\
(0.16)\end{array}$} & $\begin{array}{c}-1.01,-0.60 \\
(0.11)\end{array}$ \\
\hline & Fall & Winter & Spring & Summer & \\
\hline \multirow{2}{*}{$\begin{array}{l}\text { Commercial (kwh price) } \\
\text { short run }\end{array}$} & & & & & \\
\hline & $\begin{array}{c}-0.06, \quad 0 \\
(0.04)\end{array}$ & $\begin{array}{c}-0.04,-0.02 \\
(0.02)\end{array}$ & $\begin{array}{c}-0.14,-0.08 \\
(0.02)\end{array}$ & $\begin{array}{c}-0.10,-0.06 \\
(0.02)\end{array}$ & $\begin{array}{c}-0.08,-0.04 \\
(0.01)\end{array}$ \\
\hline \multirow{2}{*}{$\begin{array}{l}\text { Industrial (kwh price) } \\
\text { short run }\end{array}$} & $-0.12, \quad 0.10$ & $\begin{array}{ll}0, & 0.08\end{array}$ & $-0.42,-0.24$ & $-2.08,-1.64$ & $-0.71,-0.47$ \\
\hline & $\begin{array}{c}-0.78,-0.42 \\
(0.26)\end{array}$ & $\begin{array}{c}-0.66,-0.40 \\
(0.18)\end{array}$ & $\begin{array}{c}-0.98,-0.30 \\
(0.66)\end{array}$ & $\begin{array}{c}-0.16,-0.06 \\
(0.18)\end{array}$ & $\begin{array}{c}-0.64,-0.29 \\
(0.18)\end{array}$ \\
\hline long run & $-1.02,-0.14$ & $-0.86,-0.52$ & $-1.28,-0.28$ & $-0.52, \quad 0.08$ & $-0.91,-0.21$ \\
\hline $\begin{array}{l}\text { Commercial (kw price) } \\
\text { short run }\end{array}$ & $\begin{array}{c}-0.01,-0.003 \\
(0.01)\end{array}$ & $\begin{array}{c}-0.01,-0.003 \\
(0.001)\end{array}$ & $\begin{array}{c}-0.003, \\
(0.02)\end{array}$ & $\begin{array}{c}-0.01,-0.01 \\
(0.001)\end{array}$ & $\begin{array}{c}-0.01,-0.002 \\
(0.005)\end{array}$ \\
\hline \multicolumn{6}{|l|}{ Industrial (kw price) } \\
\hline short run & $\begin{array}{c}-2.08,-1.50 \\
(0.40)\end{array}$ & $\begin{array}{c}-1.92,-1.22 \\
(0.26)\end{array}$ & $\begin{array}{c}-1.98,-0.96 \\
(0.72)\end{array}$ & $\begin{array}{c}-0.70,-0.12 \\
(0.42)\end{array}$ & $\begin{array}{c}-1.66,-0.95 \\
(0.23)\end{array}$ \\
\hline $\begin{array}{l}\text { long run } \\
\text { Total system }\end{array}$ & $-2.04,-0.04$ & Total system & $-2.22,-0.66$ & $-1.10, \quad 0.02$ & $-1.74,-0.42$ \\
\hline (kwh price) short run & - & $\begin{array}{c}-0.83,-0.54 \\
(0.08)\end{array}$ & - & $\begin{array}{c}-0.33,-0.15 \\
(0.08)\end{array}$ & $\begin{array}{c}-0.62,-0.39 \\
(0.06)\end{array}$ \\
\hline \multirow{2}{*}{ (kw price) } & - & $-0.86,-0.54$ & - & $-1.10,-0.67$ & $-0.89,-0.47$ \\
\hline & - & $\begin{array}{c}-0.43,-0.27 \\
(0.06)\end{array}$ & - & $\begin{array}{c}-0.15,-0.02 \\
(0.09)\end{array}$ & $\begin{array}{c}-0.38,-0.21 \\
(0.05)\end{array}$ \\
\hline & 一 & $-0.37,-0.24$ & - & $-0.33,-0.01$ & $-0.64,-0.14$ \\
\hline $\begin{array}{l}\text { System kw peak } \\
\text { (kwh price) short run }\end{array}$ & - & - & - & $\begin{array}{c}-0.31 \\
(0.13)\end{array}$ & - \\
\hline \multirow{3}{*}{ (kw price) } & - & - & - & -0.44 & - \\
\hline & - & - & - & $\begin{array}{r}-0.06 \\
(0.03)\end{array}$ & - \\
\hline & - & - & - & -0.09 & \\
\hline
\end{tabular}

Note: Figures in parentheses are standard errors under the null hypothesis $\beta=0$.

a The lower bound of each range reflects no correction for truncation bias, the upper bound reflects correction for maximum possible bias. 
Table 7.- Ranges ${ }^{a}$ for Cross Price Elasticities with Fuel Oils Uncorrected for Bias and Corrected for MaXimum Bias

\begin{tabular}{|c|c|c|c|c|c|}
\hline & \multicolumn{2}{|c|}{ Cold } & \multicolumn{2}{|c|}{ Hot } & \multirow{3}{*}{$\begin{array}{c}\text { Annual } \\
0.02,-0.16 \\
(0.10)\end{array}$} \\
\hline \multirow[t]{2}{*}{ Residential } & \multicolumn{2}{|c|}{$\begin{array}{l}0.01,-0.14 \\
(0.12)\end{array}$} & \multicolumn{2}{|c|}{$\begin{array}{c}0.03,-0.18 \\
(0.17)\end{array}$} & \\
\hline & Fall & Winter & Spring & Summer & \\
\hline $\begin{array}{c}\text { Commercial } \\
\text { short run }\end{array}$ & - & $\begin{array}{l}0.08,-0.01 \\
(0.07)\end{array}$ & - & - & $\begin{array}{c}0.02,-0.002 \\
(0.02)\end{array}$ \\
\hline $\begin{array}{l}\text { long run } \\
\text { Industrial }\end{array}$ & - & $0.59, \quad 0.27$ & - & - & $0.15, \quad 0.07$ \\
\hline $\begin{array}{l}\text { Industrial } \\
\text { short run }\end{array}$ & $\begin{array}{l}0.27,-0.05 \\
(0.19)\end{array}$ & $\begin{array}{c}0.28, \quad 0.02 \\
(0.19)\end{array}$ & $\begin{array}{c}0.58, \quad 0.40 \\
(0.10)\end{array}$ & $\begin{array}{l}0.15,0.02 \\
(0.08)\end{array}$ & $\begin{array}{c}0.31, \quad 0.09 \\
(0.08)\end{array}$ \\
\hline $\begin{array}{l}\text { long run } \\
\text { Total system }\end{array}$ & $\begin{array}{ll}0.78, & 0.35\end{array}$ & $0.17,-0.09$ & $0.17,-0.21$ & $0.30,0.04$ & $0.37, \quad 0.03$ \\
\hline $\begin{array}{l}\text { Total system } \\
\text { short run }\end{array}$ & - & - & - & - & $\begin{array}{c}0.09,-0.04 \\
(0.05)\end{array}$ \\
\hline long run & - & - & - & - & $0.14,-0.04$ \\
\hline $\begin{array}{l}\text { System kw peak } \\
\text { short run }\end{array}$ & - & - & - & $\begin{array}{c}0.07 \\
(0.07)\end{array}$ & - \\
\hline long run & - & - & - & 0.10 & - \\
\hline
\end{tabular}

Note: Figures in parentheses are standard errors under the null hypothesis $\beta=0$.

a The upper bound of each range reflects no correction for truncation bias, the lower bound reflects correction for maximum possible bias.

The likely source of this discrepancy between $\mathrm{kw}$ peak and kwh elasticities is the increased usage of air conditioning as incomes rise.

The own price elasticity estimates are not nearly as reliable as the income elasticities, primarily because real electricity prices did not vary as much over the period as income did. Of the twenty-three customer class short run price elasticities reported, only twelve are significantly different from zero $(\alpha=.05)$. However four of the six total system short run price elasticities are significant, including the two annual system elasticities, which are six and four times their standard errors, respectively. Some of the estimated long run responses, when corrected for maximum bias, are smaller than the short run responses; this perverse result arises from some relatively large truncation biases occurring in conjunction with large sums of lag coefficients. Since the magnitude of the true bias declines with the magnitude of the elasticity, the unbiased estimates of the price elasticities will generally lie between the reported uncorrected and maximally corrected estimates; this caution is especially important in considering the reported long run elasticities.

The only consistently implausible estimated price elasticities in table 7 are the industrial $\mathrm{kw}$ demand price elasticities. One would expect these to be small relative to the industrial energy charge elasticities. Indeed, when we imposed the restriction that responses be the same in all billing districts, we found the industrial energy price elasticities to be comparable to the annual system elasticities reported in table 6 , but the demand price elasticities were then only about half the magnitude of the energy price elasticities, a much more satisfactory result. ${ }^{28}$ The magnitudes of the remaining elasticity estimates seem quite reasonable.

There are two important implications of the price elasticity estimates in table 6 . First, both the kwh price and the $\mathrm{kw}$ price elasticities of $\mathrm{kw}$ peak demand are smaller than the corresponding kwh demand elasticities. This implies that if real electricity prices rise, load factors will tend to deteriorate. Second, since price elasticities are not the same across demand and energy charges, and across seasons, manipulations of price schedules could enhance load factors, and thereby improve a utility's financial position. For example, the large price elasticity of residential users in the winter indicates that VEPCO's summer-winter price differential for residential

${ }^{28}$ We believe the problems may arise from there being considerably more heterogeneity among users in the industrial category than among customers in either the residential or commercial classes. For example, shopping centers and large office buildings are classified among industrial users along with genuine manufacturers. 
customers (with lower prices in winter) both improves load factor and increases total revenues, a double boon.

We leave it to interested readers to amuse themselves by rationalizing the elasticities in table 6. For example, are the very low summer income elasticities in the commercial sector a reflection of the fact that commercial establishments must keep their air conditioners on in the summer whether business is good or bad? And is the higher residential price response in winter over summer due to the fact that one can always put on more clothes, but there is a limit to how much one can take off?

Table 7 presents the estimated short and long run cross price elasticities with respect to alternative fuel oils. While the parameter estimates do suggest industrial and commercial customers are sensitive to the prices of alternative fuels, the standard errors are sufficiently large that we must be somewhat skeptical about such a conclusion. We conclude that if accurate projections of electricity demand are to be made, it may be necessary to estimate more precisely the demand coefficients of alternative fuels, and to forecast accurately the future behavior of those prices.

The most important finding of this paper is the seemingly strong correlations between load factor deterioration and both rising real incomes and rising real electricity prices. ${ }^{29}$ In the next ten years it is likely that real incomes will rise and real electricity prices will not fall, implying load factor deterioration for electric utilities. Moreover, in this period, utilities' reliance on nuclear power is likely to grow ${ }^{30}$ and the relatively high capital intensity of nuclear generators will increase the financial importance of load factors to utilities. Thus it is clear that electric utilities are likely to face an increasing need for means to improve load factors, or to at least retard their deterioration. One can only hope that ap-

29 There is an important caveat here for those who wish to make forecasts of electricity demand. If gas hook-ups are restricted, and users also become uncertain about future oil supplies, there may be a trend towards electric heating that could, for a summer peaking company like VEPCO, offset the deterioration in load factors caused by rising real incomes and real electricity prices.

30 It may well be that the economies of nuclear generation over alternative technologies will be sufficient to make nuclear generation, coupled with storage (by pump, battery, or otherwise), economical even in periods of deteriorating load factors. proaches such as time of day pricing will be successful in this regard.

\section{Conclusion}

In this paper we have sought to estimate a comprehensive system of demand equations for the Virginia Electric Power Company's major, non-governmental customer classes and for the system kw peak demands. We have sought to improve on previous electricity demand studies in several significant ways. First, we have given more careful attention to the declining block price structure of residential electricity prices and to the two-part tariff nature of commercial and industrial electricity price schedules. Second, we have tried to account for seasonal variation in demand coefficients, and for the dynamics of consumer demand. Third, we have used a richer, less aggregated data base than has been used in previous studies. Finally, we have integrated the analysis of kilowatt hour demand with the analysis of the system-wide kilowatt peak demand, a step not previously taken.

Our major conclusions are four. First, both growth in incomes and growth in the real price of electricity tend to induce load factor deterioration because the long run $\mathrm{kwh}$ demand income elasticity (about 0.8 ) and marginal price elasticities for both energy and demand charges (between -0.9 and -0.5 , and between -0.64 and -0.14 , respectively) are less than the corresponding kw peak demand elasticities (about 1.27 for income, -0.44 for energy charges, and -0.08 for demand charges). This finding suggests that in periods of rising real incomes and rising real electricity prices, electric utilities will increasingly feel the need for means, such as time of day pricing, to alleviate peak load problems. Second, demand elasticities vary appreciably, between and even within VEPCO's major customer classes, so that regional differences in the impact of price changes on customers are likely and the geographic distribution of new transmission and generating facilities must be carefully reckoned. Third, the prices of alternative fuels should be considered in forecasting electricity demand, since industrial customers seem responsive to these prices. And fourth, in the appendix we will find the choice between modeled and model-free forecasts is not trivial; separate forecasts of each of residential demand's deter- 
minants, coupled with structural estimates of the demand relationship yield very different forecasts of electricity demand than does direct forecasting of electricity demand.

\section{APPENDIX}

\section{Michael P. Murray and Lawrence Pulley}

\section{Modeled and Model-Free Forecasts of Residential Demand}

Forecasts of electricity demand are of interest to utilities, regulatory bodies, and many others. Forecasts based on economic models have a major advantage in that they explicitly account for the role of each determinant of demand, such as prices, income, and weather. Unfortunately, the selection and estimation of appropriate econometric models of electricity demand can make such forecasts very costly. Less costly, non-modeled forecasting techniques might be preferable to econometric methods if the forecast user can treat the demand determinants as exogenous, as, say, in the case of a utility planning future generating capacity.

One non-modeled forecasting procedure that has received much attention of late is the method of time series analysis championed by Box and Jenkins (1970). Box-Jenkins analysis does not require data on many variables, nor is it computationally demanding, yet in the arena of macro-forecasts, non-modeled predictions of this type compare favorably with those based on large econometric models of the U.S. economy (Nelson, 1972). The purpose of this paper is to compare modeled and non-modeled forecasts of residential electricity demand for that part of Virginia served by the Virginia Electric Power Company (VEPCO), for the years 1974-1983. Unfortunately, ex post comparisons of the forecasts are available only for the one, two and three period ahead forecasts (1974-76), but there are lessons to be learned from the ex ante comparisons for the remaining seven years.

The modeled forecasts of residential electricity demand are based on our model of the residential sector reported in this paper. ${ }^{1}$ In addition to a model, modeled forecasts of demand require forecasts of the independent variables of the demand model. We generated these $\mathrm{e}^{2}$ by applying Box-Jenkins techniques to past income, population, and price data, and by taking long term average temperatures for temperature forecasts, using data from 1958-1973.

The non-modeled forecasts of electricity demand were generated by applying Box-Jenkins techniques to past monthly residential electricity demand for each of VEPCO's nine billing districts. ${ }^{3}$ The resultant demand forecasts were aggregated to provide annual residential electricity demand for VEPCO's Virginia customers.

${ }^{1}$ One difference is that for forecasting purposes, prior non-positivity constraints were imposed on the price coefficients of the estimation process. This restriction affected only a small number of the estimated parameters, but the restrictions are important since over time the billing districts with perverse signs will come to dominate the results if prices tend to rise.

2 We have also made forecasts based on the population and income forecasts of state agencies. Those results are relatively similar to the modeled forecasts over the period 1974 1977 , but begin to move towards and eventually exceed the non-modeled forecasts thereafter. We believe this is due to the State's over-optimistic forecasts of future income growth in Virginia.

${ }^{3}$ In 1974, VEPCO billing districts were reorganized. We use the pre-1974 service areas.
In principle, the two forecasting techniques may be mutually consistent. Anderson (1975) has shown that a linear combination of independent mixed autoregressive-moving average (ARMA) processes is also an ARMA process. Thus, if demand is log-linear and if the (logs of the) determinants are themselves generated by ARMA processes (or if all are generated by processes that are ARMA when subjected to an identical degree of differencing), then residential electricity demand is indeed an ARMA variable itself, of the same degree. In fact, these conditions do not seem to be met in our case since not all the independent variables are identified to require the same degree of differencing to yield ARMA variables. ${ }^{4}$ Thus, we cannot expect identical forecasts from the two approaches since one or the other, or both, are misspecified. However, from a practical point of view, it would be significant even if the two procedures yielded similar results. If modeled and non-modeled forecasts of electricity demand are generally similar, ${ }^{5}$ then the less costly non-modeled approach would be preferable for all uses except those which explicitly concern changes in the determinants of demand. If the forecasts are generally dissimilar, then it becomes important to watch the comparative performances of the two procedures to judge which is superior.

Table A-1 contains the modeled and non-modeled forecasts of electricity demand for 1974-1983 and the actual growth in 1974-76 and the first quarter of 1977, all normalized with 1973 actual demand equal to 100 . It is immediately clear that the two forecast series are quite dissimilar; the modeled forecasts foresee an average growth rate of about $3.6 \%$ per year $(4.2 \%$ uncompounded), while the non-modeled forecasts anticipate an average growth rate of about $8.4 \%$ per year (12.3\% uncompounded). Thus, our results indicate that the choice between modeled and non-modeled forecasts is not trivial; separate forecasts of each demand's determinants, coupled with structural estimates of the demand relationship, yield very different forecasts of electricity demand than does direct forecasting of electricity demand. Also, on the limited data available, the modeled forecasts seem more accurate than the non-modeled forecasts. The ratio of mean square errors of prediction for non-modeled forecasts to modeled forecasts is 1.75 over the period $1974-77$, using the first quarter of 1977 to reflect the year. Our tentative conclusion is that even for uses that are not directly concerned with the determinants of demand, modeled forecasting procedures are preferable to non-modeled forecasting techniques for anticipating future electricity demands. ${ }^{6}$

After this research was completed, Boyd (1976) was brought to our attention. Several of the pieces in that collection contrast the Box-Jenkins and econometric model approaches to forecasting electric utility loads. Boyd summarizes one aspect of the discussion, noting "as the time horizon lengthens from the short run, the justification for explicitly modeling the underlying structure becomes more compelling." Thus far, our empirical results support the a priori arguments of Boyd's discussants.

4 The identified and estimated models for each of the variables used in this paper are available upon request.

${ }^{5}$ Similar, that is, when forecasts of the independent variables are used in forming the modeled forecasts. The unique aspect of modeled forecasts is that they permit consideration of alternative scenarios for these variables.

6 One must be careful not to rely too heavily on the comparison of the short run performances of the modeled and non-modeled forecasts. In the electric power industry, seven to ten years elapse between the making of capital investment plans and their fruition; the long term performance of the two procedures is very important. On this we must await 1978-85. 
THE REVIEW OF ECONOMICS AND STATISTICS

Table A-1.-Indices of Residential Electricity Demand for VEPCO's Virginia Customers

\begin{tabular}{lrrrrrrrrrr}
\hline & 1974 & 1975 & 1976 & 1977 & 1978 & 1979 & 1980 & 1981 & 1982 & 1983 \\
\hline $\begin{array}{l}\text { Modeled } \\
\quad \text { forecasts }\end{array}$ & 99.4 & 98.3 & 102.2 & 106.2 & 110.87 & 115.86 & 115.86 & 121.5 & 127.6 & 142.0 \\
$\begin{array}{l}\text { Non-modeled } \\
\quad \text { forecasts }\end{array}$ & 110.1 & 120.4 & 131.5 & 143.1 & 155.3 & 167.9 & 181.2 & 194.9 & 209.2 & 223.4 \\
Actual & 99.1 & 104.4 & 112.96 & $127.2^{\mathrm{a}}$ & - & - & - & - & - & - \\
\hline
\end{tabular}

a Based upon first quarter of 1977 over first quarter of 1976

\section{REFERENCES}

Anderson, O. D., "On a Lemma Associated with Box, Jenkins and Granger," Journal of Econometrics 3 (May 1975), 151-156.

Atkinson, S., "A Preliminary Analysis of FEA's Time of Day Electricity Pricing Experiments," unpublished, Federal Energy Administration, 1977.

Box, George, and Gwilym Jenkins, Time Series Analysis (San Francisco: Holden Day, 1970).

Boyd, J. W. (ed.), Proceedings on Forecasting Methodolog. for Time of Day and Seasonal Electric Utility Loads, Electric Power Research Institute, Palo Alto, California, 1976.

Cargill, Thomas E., and Robert A. Meyer, "Estimating the Demand for Electricity by Time of Day," Applied Economics 3 (Dec. 1971), 233-246.

Fisher, Franklin, and Carl Kaysen, A Study in Econometrics: The Demand for Electricity in the United States (Amsterdam: North-Holland Publishing Company, 1962).
Friedman, Milton, A Theory of the Consumption Function (Princeton: Princeton University Press (for National Bureau of Economic Research, 1957).

Gupta, P. C., "Statistical and Stochastic Techniques for Peak Power Demand Forecasting in Electric Utility Systems," Purdue Research and Education Center, Report No. 51, 1969.

Nelson, Charles R., "The Prediction Performance of the FRB-MIT-PENN Model of the U.S. Economy," American Economic Review 62 (Dec. 1972), 902-917.

Nordin, John, "A Proposed Modification of Taylor's Demand Analysis: Comment," Bell Journal of Economics 7 (Autumn 1976), 719-721.

Spann, Robert, and Michael Murray, "Electricity Sales and Load Forecasting in Virginia," Virginia State Corporation Commission, Richmond, Virginia, Oct. 1976.

Taylor, Lester, "The Demand for Electricity: A Survey," Bell Journal of Economics (Spring 1975), 74-110.

Uri, N., "A Mixed Time Series-Econometric Approach to Forecasting Peak System Load," unpublished, Federal Energy Administration, 1977. 